\title{
The use of a cation exchange resin for palladium-tin and palladium-indium catalysts for nitrate removal in water
}

\author{
Danns Pereira Barbosa ${ }^{\mathrm{a}, \mathrm{b}}$, Pierre Tchiéta ${ }^{\mathrm{a}, \mathrm{c}}$, Maria do Carmo Rangel ${ }^{\mathrm{b}}$, Florence Epron $^{\mathrm{a}, *}$ \\ a Institut de Chimie des Milieux et Matériaux de Poitiers, Université de Poitiers, UMR7285 CNRS, B27, 4 rue Michel Brunet, 86022 Poitiers Cedex, France

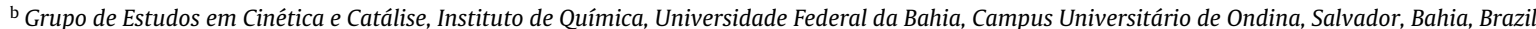 \\ ${ }^{c}$ Laboratoire de Chimie Théorique et Physique, Facultés des Sciences, Université de Yaoundé I, BP 812 Yaoundé, Cameroon
}

\section{A R T I C L E I N F O}

\section{Article history:}

Received 22 August 2012

Received in revised form 9 October 2012

Accepted 10 October 2012

Available online 18 October 2012

\section{Keywords:}

Sulfonated poly(styrene-divinylbenzene)

Palladium-tin

Palladium-indium

Nitrate reduction

\begin{abstract}
A B S T R A C T
A sulfonated poly(styrene-divinylbenzene) (Sty-DVB) was used for preparing bimetallic palladium-tin or palladium-indium catalysts by successive impregnation and catalytic reduction. The use of this acidic support allows increasing the selectivity to molecular nitrogen without external control of the $\mathrm{pH}$, as compared to a classical alumina catalyst. The preparation by successive impregnation led to the most active and selective catalysts while the indium-based catalysts were more active for nitrate reduction and less selective to nitrogen than the tin-based ones. The best performances were obtained with the $5 \% \mathrm{Pd} 2.6 \% \mathrm{Sn} / \mathrm{Sty}-\mathrm{DVB}$ prepared by successive impregnation. This finding was related to the role of the support in decreasing the final $\mathrm{pH}$, as well as to the buffering properties of the support near the active metal sites.
\end{abstract}

(c) 2012 Elsevier B.V. All rights reserved.

\section{Introduction}

The acceleration of nitrogen introduction in the soil, mainly as nitrates, is due to the increasing use of nitrogenous fertilizers, animal rearing and sanitation systems such as septic tanks. A large amount of these species permeates through the soil layers and contaminates groundwater. The human consumption of this water presents serious health risks such as blue baby syndrome, cancer, methemoglobinemia, malformation and mutation, when transformed into nitrosamines. The maximum level of nitrate, nitrite and ammonium species recommended in drinking water by the World Health Organization [1] is of $44,0.1$ and $0.5 \mathrm{mg} \mathrm{L}^{-1}$, respectively. The methods available for removing nitrate from water include physicochemical [2], biological [3] and catalytic processes [4-27]. Two types of processes are used at the industrial scale for treating nitrates, namely the physicochemical and the biological processes. The most commonly used physicochemical process for treating groundwater is the ion-exchange, which is simple to automate but presents the main disadvantage of requiring regeneration, producing large amounts of waste and increasing the chloride content of water. Biological processes, such as heterotrophic denitrification, are suitable for treatment of surface water, but are temperature sensitive, with low denitrification rates in cold water. Compared to the ion-exchange method, the biologic denitrification process

\footnotetext{
* Corresponding author.

E-mail address: florence.epron@univ-poitiers.fr (F. Epron).
}

presents the advantages of transforming nitrates into molecular nitrogen, whereas the physicochemical method only removes them from drinking water by concentrating them elsewhere. However, the main concern with the biological denitrification is the possibility of contaminating the treated water with bacteria and the need of adding a carbon source, which is often not completely used and may be another source of contamination. Moreover, biological denitrification is difficult to operate and costly post-treatment steps are needed.

An inexpensive and ecological technology for removing nitrate species from water is the catalytic reduction of nitrate species to form nitrogen. In the global reaction, nitrate is converted into nitrogen as main product, as shown by Reaction (1).

$2 \mathrm{NO}_{3}{ }^{-}+5 \mathrm{H}_{2} \rightarrow 4 \mathrm{H}_{2} \mathrm{O}+\mathrm{N}_{2}+2 \mathrm{OH}^{-}$

Nitrite, an intermediate product (Reaction (2)), can be reduced to produce nitrogen, according to Reaction (3).

$\mathrm{NO}_{3}{ }^{-}+\mathrm{H}_{2} \rightarrow \mathrm{NO}_{2}{ }^{-}+\mathrm{H}_{2} \mathrm{O}$

$2 \mathrm{NO}_{2}{ }^{-}+3 \mathrm{H}_{2} \rightarrow 2 \mathrm{H}_{2} \mathrm{O}+\mathrm{N}_{2}+2 \mathrm{OH}^{-}$

Ammonium species, a by-product of the reaction, can be formed by reduction of nitrate or nitrite species (Reactions (4) and (5)).

$\mathrm{NO}_{3}{ }^{-}+4 \mathrm{H}_{2} \rightarrow \mathrm{H}_{2} \mathrm{O}+\mathrm{NH}_{4}^{+}+2 \mathrm{OH}^{-}$

$\mathrm{NO}_{2}^{-}+3 \mathrm{H}_{2} \rightarrow \mathrm{NH}_{4}^{+}+2 \mathrm{OH}^{-}$

Hydrogen is commonly used as a reducer in this reaction. The electroneutrality of the aqueous phase is maintained by 
production of hydroxide ions [4,19]. This leads to an increase in the $\mathrm{pH}$ value of the medium up to $10-11$. It was demonstrated that this increase in $\mathrm{pH}$ favors the production of ammonium instead of molecular nitrogen, which is not acceptable for drinking water. For this reason, hydroxides ions produced during nitrate reduction are commonly neutralized by addition of hydrochloric or formic acid or $\mathrm{CO}_{2}[6,21,22,14,28-30]$.

Previous studies have shown that the best catalysts for nitrate reduction in water are bimetallic systems based on Pd modified by $\mathrm{Cu}, \mathrm{In}$ and $\mathrm{Sn}[5,10,13]$. In these catalysts, nitrate species are reduced into nitrite ones by a redox process involving the promoter, while nitrite species can be reduced by hydrogen on the monometallic Pd ensembles, to give nitrogen or ammonium [12]. Hydrogen chemisorbed on palladium also allows maintaining the second metal in the metallic state [12]. The supports used are mainly alumina or silica, but some studies with zirconia [31], niobia [32], hydrotalcite [33], zeolites [34], titania [30,35,36], ceria $[15,37]$, active carbon [18] or polymers are reported in the literature [39-46].

Recently, polymers have been considered as supports or for stabilizing the bimetallic nanoparticles in the form of colloids. Polymers such as poly(N-vinylpyrrolidone) (PVP) or poly(vinylalcohol) (PVA) were used to increase the stability and to control the particle size and the composition of the bimetallic particles $[10,46]$. Conducting polymers, especially polyaniline and polypyrrole, used as supports for bimetallic particles, have been associated with an improvement of the catalytic performances of the catalysts, in terms of both the activity and the selectivity into molecular nitrogen $[39,43,44]$. A third type of polymers, namely functional resins, has been successfully used as support for Pd-Cu and Pd-In systems for nitrate reduction $[38,40-42,45]$. Thus, it has been related the use as supports of styrene-divinylbenzene copolymer with $-\mathrm{N}\left(\mathrm{CH}_{3}\right)_{3}{ }^{+} \mathrm{Cl}^{-}$and $-\mathrm{SO}_{3}{ }^{-} \mathrm{H}^{+}$groups, i.e. cationic and anionic resins, able to exchange anions and cations, respectively. The use of acidic resins as supports for bimetallic catalysts could be an interesting alternative to the addition of acids during the course of nitrate reduction to maintain the $\mathrm{pH}$ value at acceptable levels $[38,40]$.

The aim of the present paper is to prepare bimetallic Pd-Sn and Pd-In catalysts supported on styrene-divinylbenzene copolymer with $-\mathrm{SO}_{3} \mathrm{H}$ groups and evaluate their performances in terms of activity and selectivity for nitrate reduction. Different catalyst compositions and preparation procedures are investigated. It is expected that this acidic resin used as support may play the role of buffering the reaction medium near the catalytic sites where the reaction occurs, as observed by Roveda et al. [40], and then improve the catalytic performances of the bimetallic system, thus avoiding the addition of an acid in solution.

\section{Experimental}

\subsection{Preparation of the catalysts}

The styrene (Sty) and divinylbenzene (DVB) monomers (Aldrich) were purified by distillation under reduced pressure. The $\mathrm{PdCl}_{2}$ (Alfa Aesar), $\mathrm{SnCl}_{4}$ (Alfa Aesar) and In( $\left.\mathrm{NO}_{3}\right)_{3}$ (Aldrich) were used as received.

\subsubsection{Preparation of the polymeric supports (Sty-DVB)}

The copolymer based on styrene and divinylbenzene (Sty/DVB molar ratio $=15 / 85$ ) was synthesized by polymerization in suspension using a mixture of heptane and toluene as pore forming agents dispersed in water (water to organic phase ratio equal to 4), in the presence of gelatin and hydroxyethylcellulose as stabilizing agents. In the following, the poly(Sty-DVB) support will be named Sty-DVB. Porogenic agents are used to create a macroporosity.
Benzoyl peroxide was used as initiator. After $24 \mathrm{~h}$ of reaction at $70{ }^{\circ} \mathrm{C}$, the copolymer was purified with water and then ethanol. Spheres of polymer with diameters in the $125-250 \mu \mathrm{m}$ range were used in this work. The copolymer was sulfonated in dichloroethane containing concentrated sulfuric acid. This system was kept under stirring for $4 \mathrm{~h}$ at $70^{\circ} \mathrm{C}$. The sulfonated copolymer was filtered, rinsed with water, in order to remove excess $\mathrm{H}_{2} \mathrm{SO}_{4}$, until neutral $\mathrm{pH}$ and dried at $70^{\circ} \mathrm{C}$ overnight. The ion exchange capacity, i.e. its acidity in $\mathrm{mmol}$ of $\mathrm{H}^{+}$, of the resin is $2.6 \mathrm{mmol} \mathrm{g}^{-1}$ and the BET surface area is $242 \mathrm{~m}^{2} \mathrm{~g}^{-1}$ with pore diameters between 15 and $50 \mathrm{~nm}$.

\subsubsection{Preparation of the monometallic catalysts}

The monometallic catalysts were prepared by impregnation using aqueous solution of $\mathrm{PdCl}_{2}$ in order to obtain a catalyst containing $5 \mathrm{wt}$ \% of palladium (Pd5\%/Sty-DVB). The suspension of copolymer in aqueous solution containing the palladium salt was stirred for $2 \mathrm{~h}$ at room temperature. Then water was evaporated and the catalyst was dried on a sand bath at $80^{\circ} \mathrm{C}$ and in an oven at the same temperature overnight.

\subsubsection{Preparation of the bimetallic catalysts}

Bimetallic Pd-Sn and Pd-In/polymer catalysts were prepared either by successive impregnation or by catalytic reduction method to obtain various tin and indium contents.

2.1.3.1. Preparation by successive impregnation (SI). The monometallic catalyst was added to a solution of tin $\left(\mathrm{SnCl}_{4}\right)$ or indium $\left(\operatorname{In}\left(\mathrm{NO}_{3}\right)_{3}\right)$. This mixture was stirred during $2 \mathrm{~h}$ before being evaporated and dried in a sand bath $\left(80^{\circ} \mathrm{C}\right)$ during a night.

2.1.3.2. Preparation by catalytic reduction method (CR). The palladium catalyst (Pd5\%/Sty-DVB) was flushed with $\mathrm{N}_{2}$ during 20 min then was flushed with $\mathrm{H}_{2}\left(250 \mathrm{~mL} \mathrm{~min}^{-1}\right)$ for $1 \mathrm{~h}$ at room temperature. It was shown by TPR that the palladium catalyst is completely reduced at room temperature under hydrogen. After that, a second metal solution $\left(\mathrm{SnCl}_{4}\right.$ or $\left.\mathrm{In}\left(\mathrm{NO}_{3}\right)_{3}\right)$ was added on the reduced catalyst. This deposition was performed under the same $\mathrm{H}_{2}$ flow for about $2 \mathrm{~h}$. Then, the suspension was filtered and dried at $80^{\circ} \mathrm{C}$ overnight.

\subsection{Catalytic test}

The reaction was carried out in a semi-batch reactor, at atmospheric pressure and $25^{\circ} \mathrm{C}$. The catalyst $(64 \mathrm{mg})$ was pretreated under hydrogen flow $\left(250 \mathrm{~mL} \mathrm{~min}^{-1}\right.$ at $25^{\circ} \mathrm{C}$ for $0.5 \mathrm{~h}$ ). Then, pure water $(90 \mathrm{~mL})$ was purged with nitrogen and added over the catalyst and then placed under hydrogen flow. Afterwards, $10 \mathrm{~mL}$ of a degassed nitrate solution $\left(1.6 \times 10^{-2} \mathrm{~mol} \mathrm{~L}^{-1}\right)$ was introduced in the reactor to start the reaction. The catalyst dispersion in the aqueous medium was achieved by the hydrogen flow, introduced through a porous glass located at the bottom of the reactor with a flow rate of $250 \mathrm{~mL} \mathrm{~min}^{-1}$. It was checked by using the criteria described in [47] that the chosen reaction conditions avoid any limitation by interphase mass-transfer resistances. Representative aqueous samples were periodically withdrawn and analyzed by high performance liquid chromatography.

Nitrate and nitrite were determined after separation on a C18 column using an UV detector at $\lambda=210 \mathrm{~nm}$. Ammonium ions were quantified using an Alltech Universal Cation column coupled with a conductivity detector. The acidic mobile phase (oxalic acid) used provided the complete conversion of the ammonia basic form into ammonium ions. Nitrogen was deduced by mass balance, taking into account the sum of all nitrogen-containing products.

The $\mathrm{pH}$ of the final solution was determined by means of a digital pH meter pH210 (Hanna Instruments). 
Table 1

Real content of palladium, tin and indium in the catalysts bimetallic $( \pm 0.02 \%)$.

\begin{tabular}{lllc}
\hline \multicolumn{1}{l}{ Sample } & $\%$ Pd & $\%$ Sn & \% In \\
\hline SI & & & \\
Pd5\%0.5\%Sn/Sty-DVB & 5.10 & 0.25 & - \\
Pd5\%2.0\%Sn/Sty-DVB & 5.10 & 1.25 & - \\
Pd5\%4.0\%Sn/Sty-DVB & 5.10 & 2.56 & - \\
Pd5\%0.5\%In/Sty-DVB & 5.20 & - & 0.42 \\
Pd5\%2.0\%In/Sty-DVB & 5.20 & - & 1.58 \\
Pd5\%4.0\%In/Sty-DVB & 5.20 & - & 3.20 \\
CR & & & - \\
Pd5\%0.5\%Sn/Sty-DVB & 5.20 & 0.21 & - \\
Pd5\%2.0\%Sn/Sty-DVB & 5.20 & 1.04 & 0.33 \\
Pd5\%4.0\%Sn/Sty-DVB & 5.20 & 3.70 & 1.50 \\
Pd5\%0.5\%In/Sty-DVB & 5.20 & - & 3.36 \\
Pd5\%2.0\%In/Sty-DVB & 5.20 & - & - \\
Pd5\%4.0\%In/Sty-DVB & 5.20 & - & \\
\hline
\end{tabular}

In order to quantify the amount of ammonium possibly adsorbed onto the support during the reaction, an excess of potassium cations ( $20 \mathrm{~mL}$ of a solution of $\left.\mathrm{KCl}\left(0.08 \mathrm{~mol} \mathrm{~L}^{-1}\right)\right)$ was added at the end of the reaction, with the aim of desorbing ammonium ions. Then, the concentration of ammonium was determined again [44].

The evolution of nitrates, nitrites and ammonia are systematically analyzed as a function of time. Catalysts are compared as a function of (i) their activity $\left(\mu \mathrm{mol} /\left(\min _{\text {catal }}\right)\right)$ at $75 \%$ of nitrate conversion, corresponding to the disappearance rate of nitrate per gram of catalyst and (ii) their selectivity into ammonium ions, determined as the following:

$\mathrm{S}_{\mathrm{NH}_{4}+}(\%)=\frac{\left[\mathrm{NH}_{4}^{+}\right]_{t}}{\left[\mathrm{NO}_{3}^{-}\right]_{0}-\left[\mathrm{NO}_{3}^{-}\right]_{t}} \times 100$

and

$S_{\mathrm{NO}_{2}-}(\%)=\frac{\left[\mathrm{NO}_{2}^{-}\right]_{t}}{\left[\mathrm{NO}_{3}^{-}\right]_{0}-\left[\mathrm{NO}_{3}^{-}\right]_{t}} \times 100$

where $\left[\mathrm{NO}_{3}{ }^{-}\right]_{0}$ is the initial concentration of nitrate, $\left[\mathrm{NH}_{4}{ }^{+}\right]_{t}$, $\left[\mathrm{NO}_{2}{ }^{-}\right]_{t}$ and $\left[\mathrm{NO}_{3}{ }^{-}\right]_{t}$ the concentrations of ammonium ions, nitrite and nitrate, respectively, at $75 \%$ of nitrate conversion.

The selectivity into $\mathrm{N}_{2}$ is calculated as the following:

$S_{\mathrm{N}_{2}}(\%)=100-S_{\mathrm{NH}_{4}+}(\%)-S_{\mathrm{NO}_{2}-}(\%)$

\subsection{Catalyst characterization}

The palladium, tin and indium in the catalysts were determined by ICP-OES, with a Perkin-Elmer Optima 2000 DV equipment.

The thermal stability of the samples was analyzed by TGA/DSC. The samples were runs with a TA Instruments SDT Q600 in the temperature range of $25-900^{\circ} \mathrm{C}$ under air atmosphere. It was used about $20 \mathrm{mg}$ and heating rate of $5^{\circ} \mathrm{C} \mathrm{min}^{-1}$ for all samples.

The textural properties were measured by adsorption of nitrogen at $-196^{\circ} \mathrm{C}$, in a Micromeritics TriStar-3000 apparatus. The $S_{\mathrm{BET}}$ was calculated by the BET equation, micropore specific surface $\left(S_{\text {mic }}\right)$ area were obtained using the $t$-plot method, pore volume $\left(V_{p}\right)$ and pore size distribution was determined using the BJH model.

XRD analyses were carried out in a Bruker model D5005 diffractometer. The powder method was used at ambient temperature with a wavelength of $0.1541 \mathrm{~nm}$, which corresponds to the $\mathrm{K} \alpha$ emission from a copper target $(\mathrm{K} \alpha \mathrm{Cu})$. The spectra were acquired with the software DIFFRAC and evaluated with the software EVA. The databank used comes from the International Centre for Diffraction Data (ICDD).

The catalysts were characterized by scanning electron microscopy (SEM) and transmission electron microscopy (TEM) before reaction. SEM measurements were carried out with a JEOL
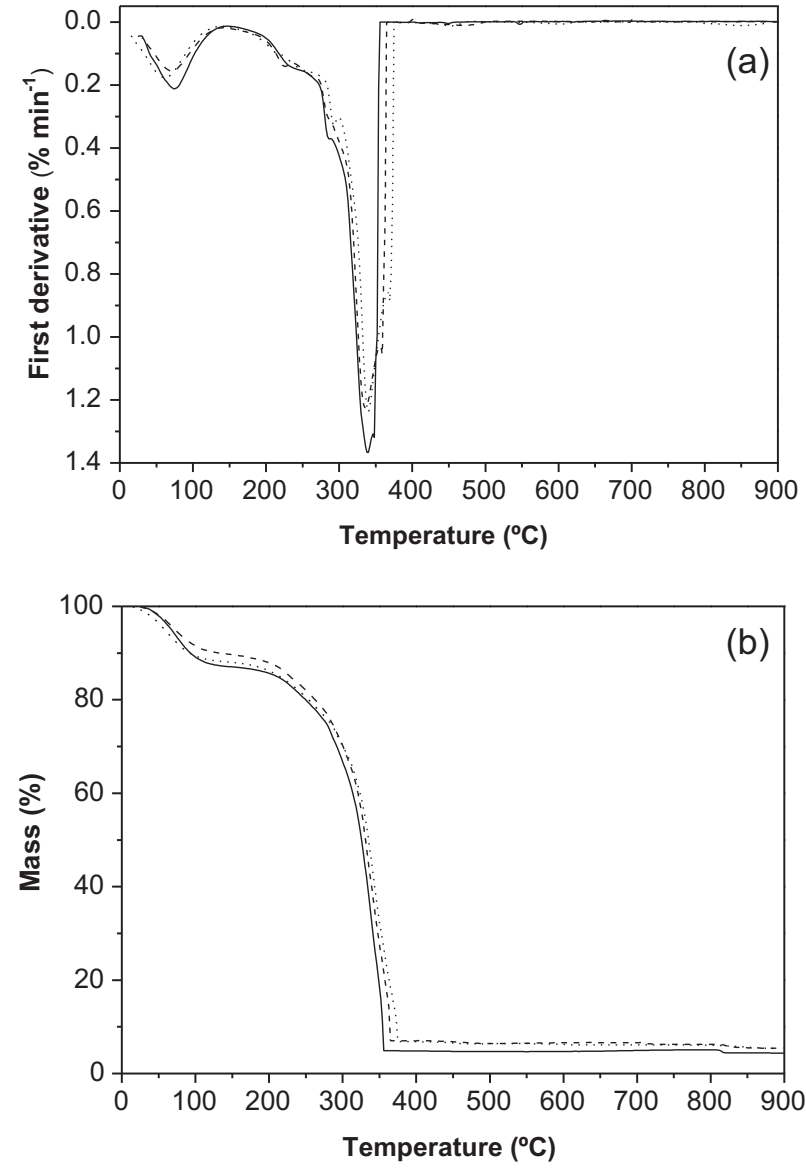

Fig. 1. TGA (a) and DTG (b) curves for (--) Pd5\%/Sty-DVB, (---) Pd5\%Sn0.5\%/Sty-DVB, and (...) Pd5\%In0.5\%/Sty-DVB.

model JSM 5600-LV equipped with an X-ray energy dispersive spectrometer (EDS, BRUKER X-Flash 4010). The samples were previously dried at $110^{\circ} \mathrm{C}$ for $2 \mathrm{~h}$, coated with gold and subjected to analysis. Before TEM analysis, the sample was embedded in epoxy resin and cut with a diamond knife in order to obtain slices of $70 \mathrm{~nm}$. TEM analysis was carried out with a JEOL 2100

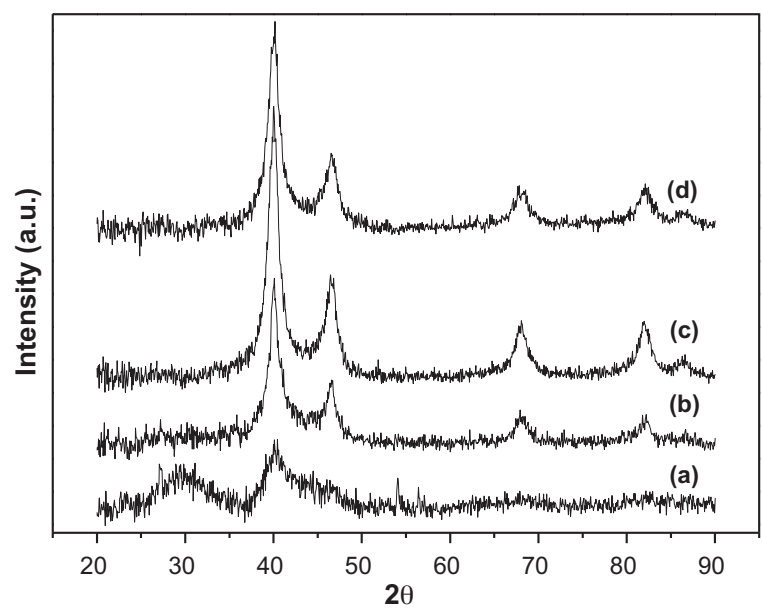

Fig. 2. X-ray diffraction for (a) Pd5\%Sn0.5\%/Sty-DVB and (b) Pd5\%In0.5\%/Sty-DVB prepared by successive impregnation method and (c) Pd5\%Sn0.5\%/Sty-DVB and (d) Pd5\%In0.5\%/Sty-DVB prepared by catalytic reduction method. All catalysts were reduced with hydrogen $250 \mathrm{~mL} \mathrm{~min}^{-1}$ for $30 \mathrm{~min}$ at room temperature. 


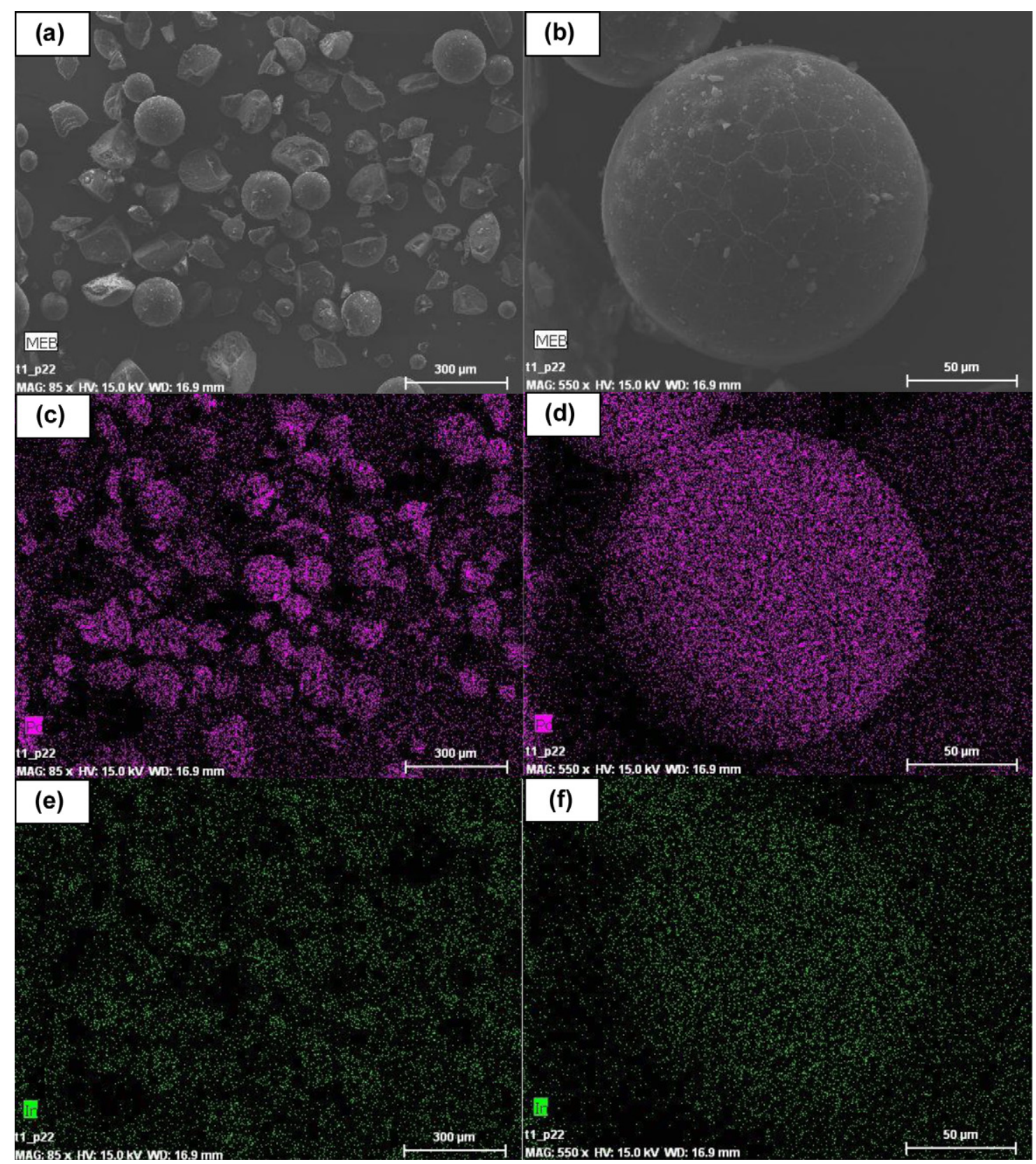

Fig. 3. SEM pictures ( $\mathrm{a}$ and $\mathrm{b}$ ) and metal mapping (c and $\mathrm{d}$ for palladium, e and $\mathrm{f}$ for indium) of Pd5\%In0.5\%/Sty-DVB prepared by successive impregnation method.

$\mathrm{LaB}_{6}$ operating at $200 \mathrm{kV}$ with a resolution of $0.19 \mathrm{~nm}$. EDS was performed with the analysis system JEOL JED.

\section{Results and discussion}

\subsection{Characterization of the catalysts}

The metal contents of the bimetallic catalysts are reported in Table 1 . The real and nominal palladium contents are similar whatever the catalyst. It can be observed a difference in the loading of the second metal depending on the preparation method. For most catalysts prepared by catalytic reduction the amount of the second metal is lower than that obtained by successive impregnation. The catalysts with indium contain more of the second metal than samples prepared with tin. It is important to mention that, after the catalytic test, the metal contents are unchanged, and then, there is no leaching of metals.
The thermogravimetric analysis (TG) and the corresponding derivative curves (DTG) of representative mono and bimetallic catalysts are shown in Fig. 1a and b. These figures show four degradation steps at roughly $70,230,285$ and $335^{\circ} \mathrm{C}$, the latter presenting a shoulder between 350 and $375^{\circ} \mathrm{C}$. The first peak at $70^{\circ} \mathrm{C}$ is due to dehydration. The two degradation steps, at 229 and $285^{\circ} \mathrm{C}$, are due to the loss of monomers, oligomers and additives used in the preparation of polymer and to the loss of $\mathrm{SO}_{3}{ }^{-}$ groups, respectively. During the last step, at $337^{\circ} \mathrm{C}$, the chain of poly(styrene-divinylbenzene) was crumbled into gaseous products [48-52]. Then, it can be concluded that the polymer is stable in the temperatures of preparation of the catalysts and the reaction catalytic of nitrates.

The nitrogen adsorption and desorption curves of the catalysts bimetallic were typical of type II isotherm. The monometallic $\mathrm{Pd} /$ Sty-DVB catalyst presents a $S_{\mathrm{BET}}$ of $190 \mathrm{~m}^{2} \mathrm{~g}^{-1}$, a micropore specific surface of $50 \mathrm{~m}^{2} \mathrm{~g}^{-1}$ and a pore volume of $0.67 \mathrm{~cm}^{3} \mathrm{~g}^{-1}$. 


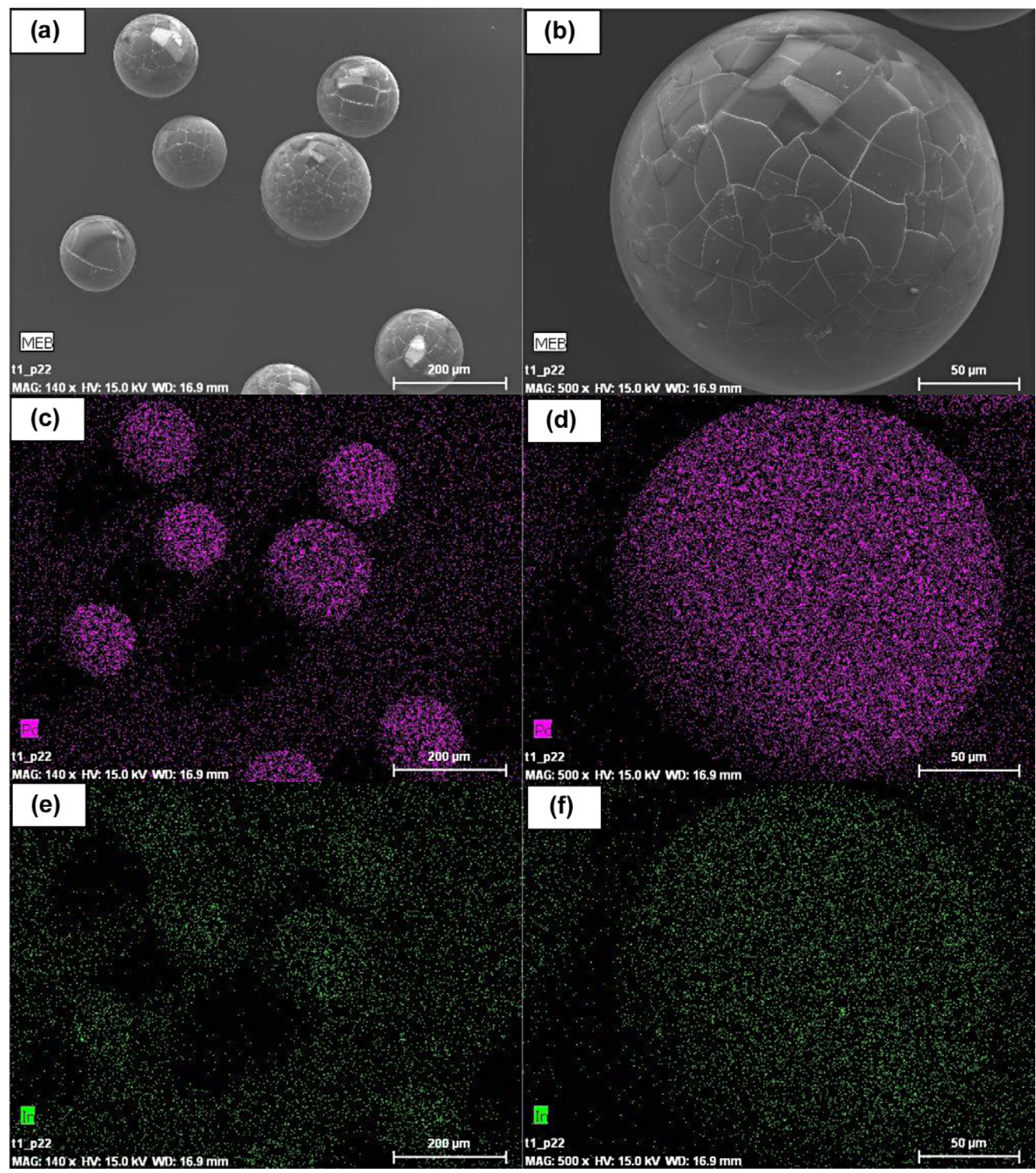

Fig. 4. SEM pictures ( $\mathrm{a}$ and $\mathrm{b}$ ) and metal mapping (c and $\mathrm{d}$ for palladium, e and f for indium) of Pd5\%In0.5\%/Sty-DVB prepared by catalytic reduction method.

The bimetallic catalysts present similar characteristics with $S_{\mathrm{BET}}$ between 172 and $189 \mathrm{~m}^{2} \mathrm{~g}^{-1}$, micropore specific surface between 35 and $40 \mathrm{~m}^{2} \mathrm{~g}^{-1}$, pore volume between 0.61 and $0.68 \mathrm{~cm}^{3} \mathrm{~g}^{-1}$. For bimetallic catalysts, the average pore diameter is between 4 and $40 \mathrm{~nm}$.

The X-ray diffractograms of bimetallic catalysts with $0.5 \mathrm{wt} \%$ of the second metal are presented in Fig. 2. Similar profiles were obtained for the samples with higher contents in second metal, except that there is an increase in the peak intensity and a decrease in the half width when the Sn or In content increases. The diffractogram of the monometallic catalysts (not shown) presents the profile of metallic palladium $\left(\mathrm{Pd}^{0}\right)$. When another metal ( $\mathrm{Sn}$ or In) was deposited (successive impregnation or catalytic reduction) on the catalyst, only the peaks characteristic of palladium $\left(\mathrm{Pd}^{0}\right)$ are visible (Fig. 2). There is no peak indicating the presence of alloys between palladium and the second metal, even in the samples with high amounts of the second metal. The palladium particle size in the bimetallic catalyst determined using Bragg equation is reported in Table 2. One can see that, for a majority of samples, the increase in the second metal loading results in an increase in the average particle size. Moreover, palladium particles are smaller in samples

\section{Table 2}

Average diameter of palladium particles, calculated by Scherrer equation, the bimetallic catalysts prepared by successive impregnation(SI) and catalytic reduction (CR)

\begin{tabular}{lll}
\hline Sample & \multicolumn{2}{l}{$D(\mathrm{~nm})$} \\
\cline { 2 - 3 } & SI & CR \\
\hline Pd5\%0.5\%Sn/Sty-DVB & 3.8 & 5.1 \\
Pd5\%2.0\%Sn/Sty-DVB & 3.9 & 6.1 \\
Pd5\%4.0\%Sn/Sty-DVB & 4.8 & 6.5 \\
Pd5\%0.5\%In/Sty-DVB & 4.6 & 5.0 \\
Pd5\%2.0\%In/Sty-DVB & 5.9 & 7.9 \\
Pd5\%4.0\%In/Sty-DVB & 6.4 & 7.9
\end{tabular}


prepared by successive impregnations than in those prepared by catalytic reduction. It has been already shown that noble metal particles sintered easily when the catalyst is immerged in water and submitted to a hydrogen bubbling [53].

The bimetallic catalysts prepared by successive impregnation and catalytic reduction with $0.5 \%$ of the second metal (indium or tin) were analyzed by scanning electron microscopy and the metals were mapped on the surface of catalysts by EDS. The microscopy pictures and metal mappings of Pd-In prepared by successive impregnation and catalytic reduction are shown in Figs. 3 and 4, respectively. The catalysts prepared by successive impregnation showed a smoother surface than those prepared by catalytic reduction (Figs. 3b and $4 \mathrm{~b}$ ). The same trend was observed with the $\mathrm{Pd}-\mathrm{Sn}$ catalysts. The cracks appearing at the surface of the samples prepared by catalytic reduction could be due to the preparation method. The mapping of metals shows that they are in general well distributed over the surface of the support, with no visible agglomeration of palladium, tin or indium metal.

In order to characterize the inner part of the polymer beads, they were embedded in a resin and then cut into thin slices which were observed by TEM. Fig. 5 shows typical TEM pictures. Metal particles are distributed everywhere in the polymer beads, with, however an apparently higher density of particles at the outer part. Metal particles are in majority very small, with an average diameter of $3 \mathrm{~nm}$, but some aggregates are also visible with diameters up to $40 \mathrm{~nm}$.

\subsection{Nitrate removal}

The sulfonated poly(styrene-divinylbenzene) support $\left(-\mathrm{SO}_{3}-\mathrm{H}^{+}\right)$is a cation exchanger. This is illustrated by the fact that, when the catalyst is introduced in a solution of potassium nitrate, as at the beginning of the catalytic test, a rapid decrease in $\mathrm{pH}$ is observed, due to the exchange between the protons of the resin and the potassium ions in solution. This kind of resin is not able to exchange anions such as nitrate $\left(\mathrm{NO}_{3}{ }^{-}\right)$or nitrite $\left(\mathrm{NO}_{2}{ }^{-}\right)$ in water. The cation exchange capacity of the resin is equal to $2.6 \mathrm{mmol} \mathrm{g}^{-1}$, which means that $0.064 \mathrm{~g}$ of support, corresponding to the amount of sample for the catalytic test, is able to exchange $1.664 \times 10^{-7} \mathrm{~mol}$ only. This value is negligible compared to the amount of nitrate in solution, i.e. $1.6 \times 10^{-4} \mathrm{~mol}$. Consequently, even if ammonium ions can be adsorbed on the resin, a maximum of $1.664 \times 10^{-7} \mathrm{~mol}$ may disappear from the solution, which would lead to a change in selectivity into ammonium ions of $0.1 \%$ at maximum. However, it was checked that ammonium ions are not exchanged in the reaction conditions. For that purpose, a solution of $\mathrm{KCl}\left(0.08 \mathrm{~mol} \mathrm{~L}^{-1}\right)$ was systematically added at the end of the catalytic nitrate removal test in order to remove potentially adsorbed ammonium ions. No ammonium desorption was observed. This can be explained by the fact that, at the beginning of the reaction, the resin is saturated by $\mathrm{K}^{+}$(in the nitrate solution), which renders it incapable for adsorbing ammonium ions, the amount of potassium in solution being thousand times greater than the amount of exchange sites.

The bimetallic Pd-Sn and Pd-In catalysts, with various second metal contents and prepared by successive impregnation or catalytic reduction, were tested in nitrate reduction in the presence of pure hydrogen. The evolution of the nitrate concentration as a function of time is reported in Fig. 6. Results obtained are summarized in Table 3.

Concerning the Pd-Sn series, one can see that the complete nitrate conversion was not reached after $27 \mathrm{~h}$ of reaction. For the SI catalysts, the activity increases significantly with the Sn content, the catalysts with the highest tin loading being by far much more active than the others. Globally the Pd-Sn catalysts prepared by successive impregnation (SI) are much more active than their
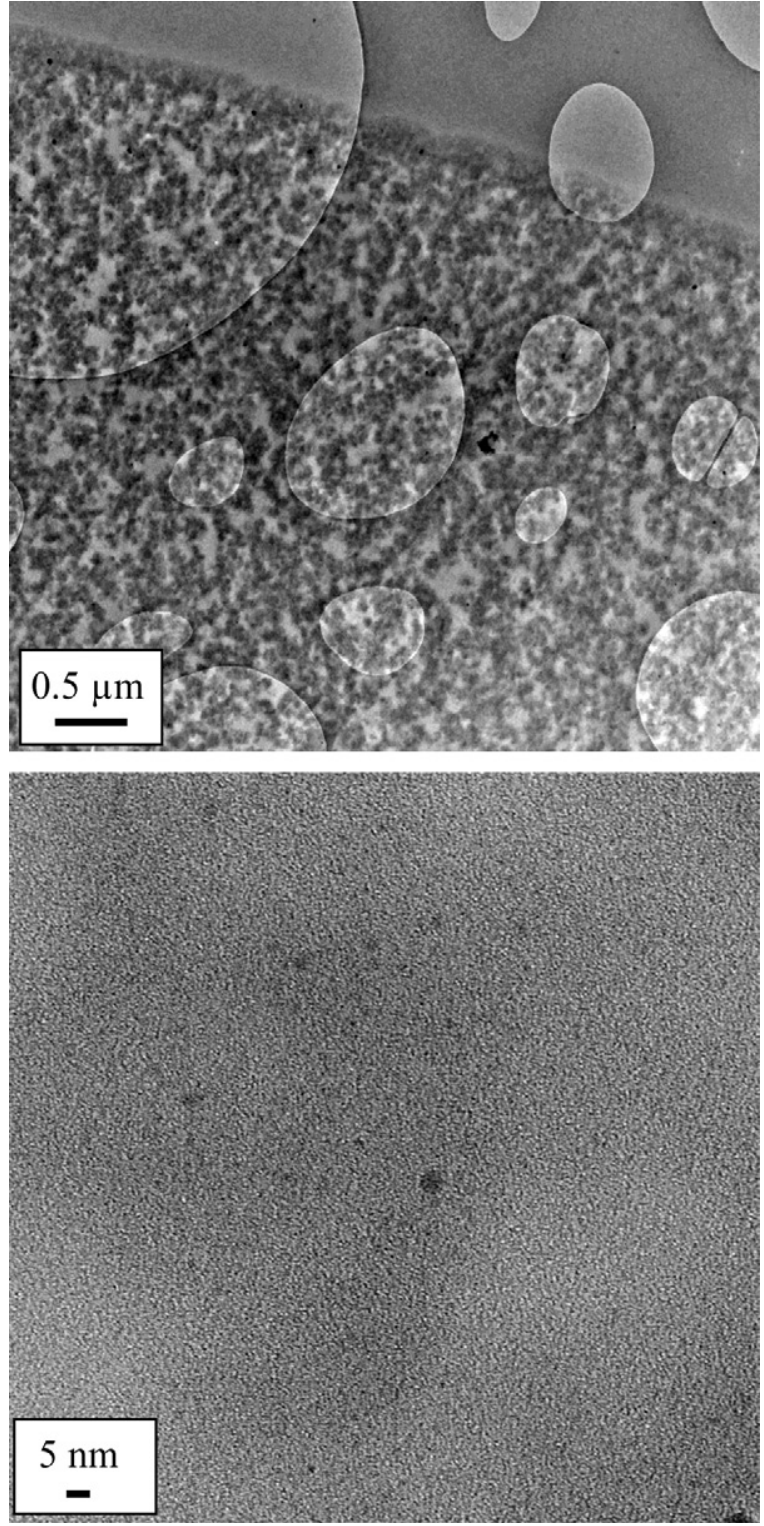

Fig. 5. TEM pictures of Pd5\%In0.5\%/Sty-DVB prepared by catalytic reduction method.

counterpart prepared by catalytic reduction (CR). The best catalyst is the one with $4 \%$ of tin added prepared by successive impregnation. This catalyst is able to convert $90 \%$ of nitrates in $40 \mathrm{~min}$, with a selectivity to $\mathrm{N}_{2}$ of $91 \%$. This selectivity reaches $93 \%$ at the complete nitrate conversion, due to nearly complete reduction of intermediate nitrite. For the CR Pd-Sn catalysts, the activity varies slightly with the tin content, but the optimal activity is obtained with the intermediate tin loading ( $2 \%$ of $\mathrm{Sn}$ ), a higher amount of tin (4\%) leading to a decrease in the activity. This can be explained by the fact that the preparation method used for the preparation of the bimetallic catalyst, i.e. the catalytic reduction, favors the deposition on tin onto palladium. Then, it can be inferred that, for a high amount of tin introduced, palladium atoms are mainly covered by tin and then the hydrogen dissociation, which occurs on palladium ensembles only, is too limited to maintain tin in the metallic state. It is now admitted that a good balance between bimetallic ensembles and palladium ensembles are necessary to obtain both a high activity in nitrate reduction and a high selectivity to gaseous nitrogen [35]. 
Table 3

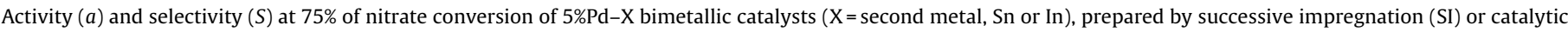
reduction (CR), in nitrate reduction under $\mathrm{H}_{2}$.

\begin{tabular}{|c|c|c|c|c|c|c|}
\hline \multirow[t]{3}{*}{ Method of preparation } & \multirow[t]{3}{*}{ Second metal } & \multicolumn{5}{|c|}{ Under $\mathrm{H}_{2}$} \\
\hline & & \multicolumn{3}{|l|}{$S(\%)$} & \multirow[t]{2}{*}{$a\left(\mu \mathrm{mol} \mathrm{min}{ }^{-1} \mathrm{~g}^{-1}\right)$} & \multirow[t]{2}{*}{$\mathrm{pH}$} \\
\hline & & $\mathrm{N}_{2}$ & $\mathrm{NH}_{4}^{+}$ & $\mathrm{NO}_{2}^{-}$ & & \\
\hline \multirow{3}{*}{ SI } & $0.5 \% \mathrm{Sn}$ & 80.0 & 19.5 & 0.5 & 2 & 8.4 \\
\hline & $2.0 \% \mathrm{Sn}$ & 87.0 & 13.0 & 0 & 5 & 8.9 \\
\hline & $4.0 \% \mathrm{Sn}$ & 91.0 & 7.0 & 2.0 & 74 & 8.4 \\
\hline \multirow{3}{*}{$\mathrm{CR}$} & $0.5 \% \mathrm{Sn}$ & 87.0 & 9.1 & 3.9 & 4 & 9.7 \\
\hline & $2.0 \% \mathrm{Sn}$ & 72.0 & 17.4 & 10.6 & 6 & 9.2 \\
\hline & $4.0 \% \mathrm{Sn}$ & 89.0 & 6.7 & 4.3 & 4 & 9.3 \\
\hline \multirow{3}{*}{ SI } & $0.5 \%$ In & 84.5 & 15.5 & 0.0 & 10 & 9.9 \\
\hline & $2.0 \%$ In & 81.0 & 6.0 & 13.0 & 14 & 9.3 \\
\hline & $4.0 \%$ In & 88.0 & 3.0 & 9.0 & 28 & 8.2 \\
\hline \multirow{3}{*}{$\mathrm{CR}$} & $0.5 \%$ In & 75.8 & 11.6 & 12.6 & 6 & 9.5 \\
\hline & $2.0 \%$ In & 42.0 & 41.7 & 16.3 & 12 & 9.4 \\
\hline & $4.0 \% \operatorname{In}$ & 40.3 & 16.2 & 43.5 & 7 & 9.1 \\
\hline
\end{tabular}

As far as the Pd-In catalysts are concerned, they present higher activities, at $75 \%$ of nitrate conversion, than their Pd-Sn counterpart, especially for low metal loadings $(\leq 2 \%)$, whatever the preparation method. Moreover, all the Pd-In catalysts are able to convert totally nitrates. However, the selectivity to nitrogen is always lower than that obtained with Pd-Sn catalysts, which is due to a high selectivity to ammonium, as well as to the high amount of nitrite produced. As for the Pd-Sn series, the best catalytic performances in terms of activity and selectivity to $\mathrm{N}_{2}$ were obtained with the catalysts prepared by successive impregnation.

Very few studies deal with the use of resins as supports for bimetallic catalysts for an application in nitrate removal, and,
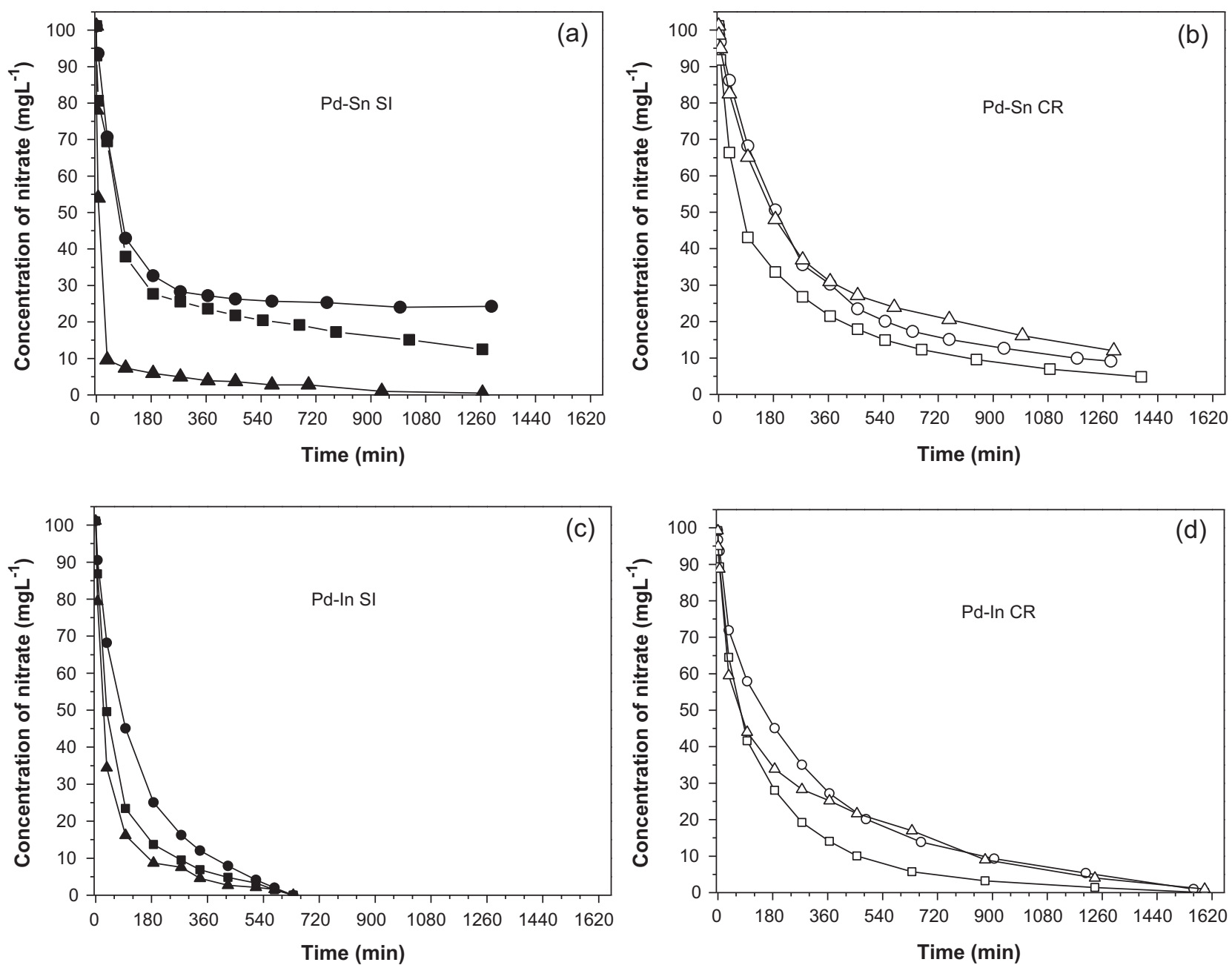

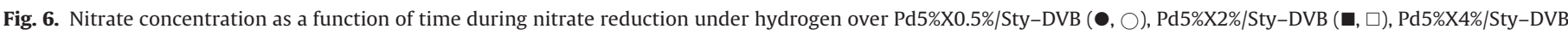
$(\boldsymbol{\Lambda}, \Delta)(\mathrm{X}=$ Sn or In) prepared by successive impregnation method (full symbol-a and c) and catalytic reduction (empty symbol-b and d). 
Table 4

Comparison of the catalytic performances at $75 \%$ of nitrate conversion, of $5 \% \mathrm{Pd}-2 \% \mathrm{X}$ bimetallic catalysts $(\mathrm{X}=$ second metal, $\mathrm{Sn}$ or $\mathrm{In}$ ) prepared by successive impregnation and supported on the resin or $\mathrm{Al}_{2} \mathrm{O}_{3}$, in nitrate reduction under pure $\mathrm{H}_{2}$.

\begin{tabular}{lllc}
\hline Catalyst & $\begin{array}{l}\text { Activity } \\
\left(\mu \mathrm{mol} \mathrm{g}^{-1} \mathrm{~min}^{-1}\right)\end{array}$ & $\begin{array}{l}\text { Selectivity to } \\
\mathrm{N}_{2}(\%)\end{array}$ & Final pH \\
\hline $\mathrm{Pd}-\mathrm{Sn} /$ Sty-DVB & 5 & 87 & 8.9 \\
$\mathrm{Pd}-\mathrm{In} / \mathrm{Sty}-\mathrm{DVB}$ & 14 & 81 & 9.3 \\
$\mathrm{Pd}-\mathrm{Sn} / \mathrm{Al}_{2} \mathrm{O}_{3}$ & 32 & 55 & 10.0 \\
$\mathrm{Pd}-\mathrm{In} / \mathrm{Al}_{2} \mathrm{O}_{3}$ & 71 & 52 & 10.3 \\
\hline
\end{tabular}

mainly, cationic resins, i.e. with anion exchange capacity, were used $[41,45]$. With the cationic resins, the objective was to concentrate nitrate in the support by ionic forces in order to favor the catalytic reduction. However, it was shown that the activity of $\mathrm{Pd}-\mathrm{Cu}$ and $\mathrm{Pd}-\mathrm{In}$ catalysts supported on a macroporous weak anionic exchange resin [45] is not directly related to the capacity of the resin of retaining nitrate. To the best of our knowledge, only two papers $[38,40]$ report the use of an anionic resin as support for this application, with the aim of buffering the $\mathrm{pH}$ values within the pores of the catalyst. Two kinds of resins were used, namely a strong acidic one, with sulfonic acid groups [38] and a weakly acidic one baring carboxylic acid groups [40]. Thus, Gašparoviĉová et al. [38] studied nitrate reduction on $\mathrm{Pd}-\mathrm{Cu}$ catalysts supported on the $\mathrm{H}^{+}$ form of a commercial Sty-DVB copolymer (Dowex 50 WX4), sulfonated by treatment in sulfuric acid. During nitrate reduction, a low selectivity to $\mathrm{NH}_{4}{ }^{+}$was observed with highly acidic supports, which was due to the capacity of the resin to trap all the cations present in solution. It was shown that the best catalyst in terms of activity and selectivity was the one prepared by coimpregnation and activated under hydrogen at $50^{\circ} \mathrm{C}$, presenting a final acidity of $3.9 \mathrm{~mol} / \mathrm{Kg}$. Roughly $60 \%$ of nitrate conversion was reached with this catalyst in more than $210 \mathrm{~min}$. However, in the presence of this kind of catalysts, a large amount of ammonium ions is produced and even if they are trapped by the resin, this is not satisfying in term of selectivity to nitrogen gas. The Dowex 50 WX4 used as support in [38] is a gel-type, i.e. microporous resin, deprived of pores in the dry state, which becomes accessible to the reactants only after swelling in an appropriate solvent, as water in the case of the sulfonated resin. With this kind of resin as support, a low activity was observed due to diffusive effects and then to the difficulty for the reactants for reaching active sites inside the polymeric beads. On the other hand, the sulfonated Sty-DVB copolymer support synthesized in the present study is different, since it is a macromolecular resin, with high surface area, in the dry state. In the swollen state, i.e. in water as during the catalytic test, the accessibility of the reactants to the metal nanoparticles dispersed in the matrix is very high. Consequently, a complete nitrate conversion can be reached in $90 \mathrm{~min}$ of reaction with the best catalyst formulation. In addition, the buffering properties of the support near the active metal sites provided high selectivity to nitrogen to the catalysts. The best formulation was achieved by the Pd-X/Sty-DVB catalysts, which has been proven to be the most active and selective to nitrogen.

The performances of the Pd-Sn and Pd-In catalysts supported on the sulfonated copolymer were compared to their counterpart supported on alumina, prepared in the same way, by successive impregnation, and with the same metal loading, under pure hydrogen, i.e. without any external control of the $\mathrm{pH}$ by addition of an acid in the medium. Results are summarized in Table 4. One can see that, the use of the sulfonated copolymer as support allows to obtain higher nitrogen selectivities than those obtained with the aluminasupported bimetallic catalysts, even if the activity are much lower. This could be easily explained by the lower final $\mathrm{pH}$ obtained in the presence of the Pd-X/Sty-DVB catalysts, as well as to the buffering properties of the support near the active metal sites.

\section{Conclusion}

It is well known that the key point of catalytic nitrate reduction for obtaining a high selectivity to gaseous nitrogen is the $\mathrm{pH}$ of the solution. The most active and selective catalysts for this reaction are made up of palladium and tin or indium as promoters with redox properties, and high interactions between two types of metals $[12,15]$. The problem with nitrate reduction is that the formation of ammonium, an undesirable product, always occurs. Until now there is no paper reporting a selectivity to $\mathrm{N}_{2}$ of $100 \%$. All the possible noble metals and promoters, as well as the effect of the experimental conditions ( $\mathrm{pH}$, partial pressure of $\mathrm{H}_{2}$, amount of catalyst, metal loading method of preparation, etc.) have already been studied. The use of a new type of support well adapted to water treatment may help to improve the catalytic performances. Nitrate reduction is a reaction performed at room temperature and pressure and for this reason it is a good reaction for developing new types of supports. The ambition of our study was to use a new type of support with the aim of improving the selectivity to $\mathrm{N}_{2}$.

Palladium-tin and palladium-indium bimetallic systems were deposited on a sulfonated styrene-divinylbenzene copolymer by successive impregnation and catalytic reduction, this method favoring the deposition of the second metal onto palladium. The preparation method affects the amount of metal deposited and the size of bimetallic particles. Whatever the preparation method used, a high surface area in the dry state and thermal stability up to about $200^{\circ} \mathrm{C}$ were obtained for the catalysts. Also, the metals were homogeneously distributed on the support surface. The bimetallic catalysts prepared with indium are more active and less selective than catalysts prepared with tin. The catalysts with tin were more active and selective to $\mathrm{N}_{2}$ when prepared by successive impregnation, compared to those prepared by catalytic reduction. The best catalyst in terms of activity and selectivity to $\mathrm{N}_{2}$ is the one prepared by successive impregnation and containing $4 \%$ of Sn $(2.6 \%$ of Sn deposited). This catalyst is able to convert $90 \%$ of nitrates in 40 min under pure hydrogen. At $100 \%$ of nitrate conversion, there is nearly no nitrite in solution and the selectivity to $\mathrm{N}_{2}$ is of $93 \%$. This can be related to the role of the support in buffering the active metal sites increasing the catalyst selectivity to nitrogen.

\section{Acknowledgments}

The authors thank the CAPES/COFECUB (Ph 603/08) for the financial support.

P. Tchieta thanks the IC2MP of the University of Poitiers (France) and ACP-CAM (Cameroon) for his fellowship.

\section{References}

[1] M. Sheffer, Guidelines for Drinking-water Quality, vol. 1, 3rd edition, World Health Organization, Geneva, 2008, p. 418.

[2] A. Kapoor, T. Viraraghavan, J. Environ. Eng. 4 (1997) 371-380.

[3] J.M. Flere, T.C. Zhang, J. Environ. Eng. 125 (1999) 721-729.

[4] S. Hörold, T. Tacke, K.-D. Vorlop, Environ. Technol. 14 (10) (1993) 931-939.

[5] S. Hörold, K.-D. Vorlop, T. Tacke, M. Sell, Catal. Today 17 (1993) 21-30.

[6] U. Prüsse, S. Hörold, K.-D. Vorlop, Chem. Ing. Tech. 69 (1-2) (1997) 93-97.

[7] M. Hählein, U. Prüsse, J. Daum, V. Morawsky, M. Kröger, M. Schröder, M. Schnabel, K.D. Vorlop, in: B. Delmon, et al. (Eds.), Preparation of Catalysts, vol. VIII, Elsevier, Amsterdam, 1998, pp. 99-107.

[8] A. Pintar, J. Batista, Catal. Today 53 (1999) 35-50.

[9] A. Lecloux, Chem. Catal. Today 53 (1999) 23-34.

[10] U. Prüsse, M. Hähnlein, J. Daum, K.-D. Vorlop, Catal. Today 55 (2000) 79-90.

[11] A. Pintar, J. Batista, J. Levec, Catal. Today 66 (2001) 503-510.

[12] F. Epron, F. Gauthard, C. Pinéda, J. Barbier, J. Catal. 198 (2001) 309-318.

[13] U. Prüsse, K.-D. Vorlop, J. Mol. Catal. A. 173 (2001) 313-328.

[14] J. Sá, D. Gašparoviĉová, K. Hayek, E. Halwax, J.A. Anderson, H. Vinek, Catal. Lett. 105 (2005) 209-217.

[15] F. Epron, F. Gauthard, J. Barbier, J. Catal. 206 (2002) 363-367.

[16] M.J. Chollier-Brym, R. Gavagnin, G. Strukul, M. Marella, M. Tomaselli, P. Ruiz, Catal. Today 75 (2002) 49-55. 
[17] L. Lemaignen, C. Tong, V. Begon, R. Burch, D. Chadwick, Catal. Today 75 (2002) 43-48.

[18] Y. Yoshinaga, T. Akita, I. Mikami, T. Okuhara, J. Catal. 207 (2002) 37-45.

[19] F. Deganello, L.F. Liotta, A. Macaluso, A.M. Venezia, G. Deganello, Appl. Catal. B: Environ. 24 (2000) 265-273.

[20] F. Epron, F. Gauthard, J. Barbier, J. Catal. 220 (2003) 182-191.

[21] M. D’Arino, F. Pinna, G. Strukul, Appl. Catal. B 53 (3) (2004) 161-168.

[22] A. Garron, F. Epron, Water Res. 39 (2005) 3073-3081.

[23] A. Garron, K. Lázár, F. Epron, Appl. Catal. B 59 (2005) 57-69.

[24] A. Garron, K. Lazar, F. Epron, Appl. Catal. B: Environ. 65 (2006) 240-248

[25] Y. Wang, J. Qu, H. Liu, J. Mol. Catal. A: Chem. 272 (2007) 31-37.

[26] G. Centi, S. Perathoner, Appl. Catal. B 41 (2003) 15-29.

[27] Y. Wang, J. Qu, H. Liu, C. Hu, Catal. Today 126 (2007) 476-482.

[28] G. Stukul, F. Pinna, M. Marella, L. Meregalli, M. Tomaselli, Catal. Today 27 (1996) 209-214.

[29] A. Pintar, J. Batista, J. Levec, T. Kajiuchi, Appl. Catal. B: Environ. 11 (1996) 81-98.

[30] N. Wehbe, M. Jaafar, C. Guillard, J.M. Herrmann, S. Miachon, E. Puzenat, N. Guilhaume, Appl. Catal. A 368 (2009) 18.

[31] Z.Y. Xu, L.Q. Chen, Y. Shao, D.Q. Yin, S.R. Zheng, Ind. Eng. Chem. Res. 48 (2009) 8356-8363.

[32] M.P. Maia, M.A. Rodrigues, F.B. Passos, Catal. Today 123 (2007) 171-176.

[33] A.E. Palomares, J.G. Prato, F. Marquez, A. Corma, Appl. Catal. B 41 (2003) 3-13.

[34] R. Rodriguez, C. Pfaff, L. Melo, P. Betancourt, Catal. Today 107-108 (2005) 100-105.

[35] F. Zhang, S. Miao, Y. Yang, X. Zhang, J. Chen, N. Guan, J. Phys. Chem. C 112 (2008) 7665-7671.
[36] W.L. Gao, N.J. Guan, J.X. Chen, X.X. Guan, R.C. Jin, H.S. Zeng, Z.G. Liu, F.X. Zhang, Appl. Catal. B 46 (2003) 341-351.

[37] A. Devadas, S. Vasudevan, F. Epron, J. Hazard. Mater. 185 (2011) 1412-1417.

[38] D. Gašparoviĉová, M. Králik, M. Hronec, Collect. Czech. Chem. Commun. 64 (1999) 502-514

[39] E. Gautron, A. Garron, E. Bost, F. Epron, Catal. Commun. 4 (2003) 435-439.

[40] A. Roveda, A. Benedetti, F. Pinna, Inorg. Chim. Acta 349 (2003) 203-208.

[41] D. Gašparoviĉová, M. Kralik, M. Hronec, A. Biffis, M. Zecca, B. Corain, J. Mol. Catal. A: Chem. 244 (2006) 258-266.

[42] D. Gašparoviĉ́ová, M. Kralik, M. Hronec, A. Biffis, Z. Vallusová, H. Vinek, B. Corain J. Mol. Catal. A: Chem. 264 (2007) 93-102.

[43] I. Dodouche, F. Epron, Appl. Catal. B: Environ. 76 (2007) 291-299.

[44] I. Dodouche, D.P. Barbosa, M.C. Rangel, F. Epron, Appl. Catal. B: Environ. 93 (2009) 50-55.

[45] C. Neyertz, F.A. Marchesini, A. Boix, E. Miró, C. Querini, Appl. Catal. A: Gen. 372 (2010) 40-47.

[46] K.A. Guy, H.P. Xu, J.C. Yang, C.J. Werth, J.R. Shapley, J. Phys. Chem. C 113 (2009) 8177-8185.

[47] H. Wan, R.V. Chaudhari, B. Subramanian, Top. Catal. 55 (2012) 129-139.

[48] P.W. Yen, T.C. Chou, Appl. Catal. A: Gen. 198 (2000) 23-31.

[49] L.C. Costa, A.S. Gomes, F.M.B. Coutinho, V.G. Teixeira, React. Funct. Polym. 70 (2010) 738-746

[50] C.D. Vlad, M.V. Dinu, S. Dragan, Polym. Degrad. Stab. 79 (2003) 153-159.

[51] M. Kocirik, J. Brych, J. Hradil, Carbon 39 (2001) 1919-1928.

[52] K. Bratek, W. Bratek, M. Kulazynski, Carbon 40 (2002) 2213-2220.

[53] A. Douidah, P. Marecot, S. Labruquere, J. Barbier, Appl. Catal. A 210 (2001) 111-120. 